\title{
Erenumab Decreases Headache-Related Sick Leave Days and Health Care Visits: A Retrospective Real- World Study in Working Patients with Migraine
}

\author{
Henri Autio (D) · Timo Purmonen · Samu Kurki · Emina Mocevic • \\ Minna A. Korolainen · Samuli Tuominen · Mariann I. Lassenius • \\ Markku Nissilä
}

Received: September 18, 2021 / Accepted: November 16, 2021 / Published online: December 10, 2021

(c) The Author(s) 2021

\section{ABSTRACT}

Introduction: The prevalence of migraine is highest among working age individuals, and this disease is associated with an increased number of sick leaves and health care visits, as well as lost productivity. Erenumab, the first monoclonal antibody targeting the calcitonin gene-related peptide (CGRP) pathway, is effective in decreasing the monthly number of migraine days, but evidence of its impact on the number of sick leave days and health care visits in patients with migraine is limited.

Methods: This retrospective registry study focused on occupationally active patients with migraine treated with erenumab at a Finnish private health care provider, Terveystalo. Erenumab responders, defined as patients who had

Supplementary Information The online version contains supplementary material available at https:// doi.org/10.1007/s40120-021-00303-x.

H. Autio $(\bowtie) \cdot$ T. Purmonen · M. A. Korolainen Novartis Finland Oy, Metsänneidonkuja 10, 02130 Espoo, Finland

e-mail: henri.autio@novartis.com

S. Kurki · M. Nissilä

Terveystalo Biobank, Turku, Finland

E. Mocevic

Novartis Healthcare A/S, Copenhagen, Denmark

S. Tuominen · M. I. Lassenius

Medaffcon Oy, Espoo, Finland at least two unique prescriptions of erenumab and no prescription of other CGRP inhibitor (CGRPi), were followed for 12 months prior to and after erenumab treatment initiation (index), and the change in the number of headache-related and all-cause sick leave days, health care visits and prescriptions for other medications during this period were assessed from the registry data. The same outcomes were assessed in an age- and sex-matched control group of migraine patients not receiving CGRPi to control for potential changes in patient behavior and health care practices during the COVID-19 pandemic.

Results: Altogether, 162 patients who were entitled to employer-sponsored health care received erenumab and met the 12-month follow-up requirements. In the responder group $(n=82 ; 50.1 \%)$ headache-related sick leave days were reduced by $73.9 \%(p=0.035)$ and health care visits by $44.6 \%(p<0.001)$ in the 12 months following treatment initiation compared to the period of 12 months prior to treatment. All-cause sick leave days were reduced by $19.4 \%$ and all-cause health care visits by $13.5 \%$, but these changes were not statistically significant. Triptan prescriptions decreased by $30.4 \%(p=0.012)$ and other prophylactic treatments by $31.5 \%(p=0.004)$. No significant changes were observed in the corresponding outcomes in the migraine control group during the same period. 
Conclusions: The results of this registry study suggest that in addition to the effect on the monthly number of migraine days documented in clinical trials, erenumab can significantly reduce the number of headache-related sick leave days and health care visits in employed patients with migraine managed in routine clinical practice.

Keywords: Calcitonin gene-related peptide; Erenumab; Health care visits; Migraine; Realworld evidence; Sick leaves; Working impairment

\section{Key Summary Points}

\section{Why carry out this study?}

Migraine is common among the working age population, and this disease is associated with an increased number of sick leave days and health care visits, as well as lost productivity.

Erenumab, an inhibitor of the calcitonin gene-related peptide pathway, reduces the monthly number of migraine days, but limited information is currently available on its effect on working impairment.

The aim of this registry study was to explore the effect of erenumab on the number of sick leave days and health care visits in patients with migraine.

\section{What was learned from the study?}

Erenumab reduced the number of headache-related sick leave days by $73.9 \%$ and the number of health care visits by $44.6 \%$ in the 12 months following treatment initiation among treatment responders.

This study shows that effective prophylactic management of migraine with erenumab may reduce sick leaves and health care resource use related to the disease.

\section{INTRODUCTION}

Migraine is globally among the leading causes of disability according to the number of years lived with disability metric [1]. This neurological disease particularly affects people in their prime working years and is not only associated with decreased quality of life but also with work impairment resulting in a significant economic burden on societies [2-5]. Several studies have demonstrated the association between migraine and an increased number of sick leave days, productivity loss and increased health care resource use [2, 6-8]. In one survey, $70 \%$ of migraine patients reported that migraine had affected their working life, and $60 \%$ of responders reported to have missed at least 1 day of work in the last month due to migraine, with an average of 4.5 days missed in the last month [3]. One half of the responders reported overall work impairment in the previous week due to migraine and, notably, one in four patients with chronic migraine reported to have lost their jobs due to migraine [3, 9]. Surveys further indicate that employers may not always fully understand the nature of the disease nor consider headache as an acceptable explanation for lower productivity and absenteeism [10], which can make the inability to work due to headache highly stigmatizing for the affected individual $[10,11]$.

Indirect costs resulting from absenteeism and productivity loss are the main contributors to the economic burden of migraine and could represent as much as $80-90 \%$ of the economic burden of the disease $[2,7,8]$. The detrimental impact of migraine on the ability to work increases with disease severity, with the highest burden observed in patients with chronic migraine and those for whom multiple prophylactic treatments have failed [3, 6, 8, 9]. In addition to costs attributed to productivity loss, migraine is also associated with direct health care utilization-related costs, which also increase with disease severity $[2,6]$.

Thus, there is a clear need for effective management of migraine. From an economic standpoint, reducing the impact of migraine on working disability is a key treatment objective. 
The recent introduction of monoclonal antibodies against the calcitonin gene-related peptide (CGRP) pathway has broadened the spectrum of treatment options available for patients with chronic and episodic migraine [12-15]. Erenumab, the first monoclonal antibody targeting the CGRP pathway through inhibition of the CGRP receptor, reduces the number of monthly migraine days (MMD) in patients with episodic or chronic migraine [14, 16-18]. In addition to data from controlled clinical trials, growing evidence from real-world clinical practice demonstrates the beneficial effect of erenumab on monthly number of migraine and headache days [19-22].

In addition, an exploratory analysis of a phase III clinical trial suggested that erenumab may have a favorable effect on both absenteeism and presenteeism in patients with chronic migraine [23]. However, the real-world impact of erenumab treatment on sick leave days and health care visits has not been formally studied. Therefore, the objective of this study was to assess the impact of erenumab treatment on the number of sick leave days and health care visits in a cohort of working migraine patients.

\section{METHODS}

\section{Patient selection and data source}

In this retrospective registry study, we identified all migraine patients treated with erenumab at a private nationwide health care provider, Terveystalo (Finland). The electronic health records of Terveystalo contain data from 1.1 million Finnish patients who have given their consent for registry studies, representing $20 \%$ of the general population of Finland. The database contains data on employment/occupational health care status, diagnoses, procedures, prescriptions, laboratory measures, demographical characteristics and sick leave days; as such, the data reflect true clinical data instead of claims. The registry has been described in detail in previous publications [6, 24]. This study was approved as a non-interventional retrospective registry study by the Terveystalo Institutional
Review Board on 10 April 2019 (20190410-A) in accordance with the Data Protection Act (1050/ 2018), and access to the data was granted by Terveystalo. The database was only accessed by Terveystalo statistician, who provided the aggregated data and performed the statistical analyses. All patients had given their informed consent for secondary use of health data to Terveystalo in a format that has been approved by the National Institute of Health and Welfare, Finland. All data were analyzed in pseudonymized format and published in aggregate such that an individual subject cannot be identified. This study was performed in accordance with the Helsinki Declaration of 1964 and its later amendments.

The aim of this study was to focus specifically on working patients with migraine. According to Finnish law, all employers must provide basic occupational health care services to all employees. Our analyses were restricted to those patients with employer-sponsored health care (occupational health care) at Terveystalo to ensure that the study subjects were employed and had comprehensive follow-up of care at one health care provider.

Patients initiating erenumab treatment between 20 September 2018 and 15 October 2019 were included in the study, and data on sick leave days, health care visits as well as medications based on prescriptions were assessed 12 months prior to and 12 months after treatment initiation (index date). Consequently, a 1-year follow-up prior to and after erenumab initiation was required for all patients.

We hypothesized that the effect of erenumab on the number of sick leave days and health care visits is additive to the clinical effect of erenumab and therefore focused on patients who responded to treatment with erenumab. To identify treatment responders we utilized national payer reimbursement criteria for erenumab. In Finland, patients can receive reimbursement for erenumab if they have episodic or chronic migraine with $\geq 8 \mathrm{MMD}$ and $\geq 2$ failed prophylactic treatments. Patients have to be assessed after 12 weeks of treatment, and reimbursement may continue if the patient has experienced $\geq 50 \%$ decrease in MMDs. 
Therefore, a second unique prescription of erenumab for the same patient was taken to indirectly indicate that the patient showed a clinical response to erenumab treatment of the abovementioned magnitude. Consequently, responders were defined as patients with at least two unique prescriptions of erenumab within 6 months and no transition to another CGRP inhibitor based on prescriptions during the follow-up period.

\section{Controls}

To control for variations in sick leaves and health care visits associated with potential changes in patient behavior and health care practices during the COVID-19 pandemic, a one-to-one age- and gender-matched control group was created. The patients in the control group were selected based on having received at least one triptan prescription for migraine after 2018. The index date of the control was set as the date of the first erenumab prescription in the corresponding case.

\section{Sick leave days and health care visits}

Changes in the number of sick leave days and health care visits and in prescribed medications during the 12 months preceding erenumab treatment (pre-index) were compared to the 12 months after initiation of treatment (postindex). In a sensitivity analysis, the results were separately assessed for the period of 6 to 12 months post-index. This time frame was included to assess the number of sick leave days and health care visits during a period when erenumab treatment may be assumed to have reached its clinical effect in the majority of patients. For the control group the same outcomes were assessed 12 months pre- and postindex of the corresponding case. Sick leave days and health care visits with the main diagnosis of migraine (International Classification of Diseases, Tenth Revision, Clinical Modification [ICD-10-CM] code G43*), other headache syndrome $\left(\mathrm{G} 44^{*}\right)$ and headache (R51*) were together considered to be headache related. Analysis of all-cause sick leave days and health care visits included all sick leaves and visits regardless of diagnosis code.

\section{Medications}

Changes in all-cause drug prescriptions were assessed 12 months pre-index versus post-index from the electronic health records. For the analysis, drugs were categorized based on Anatomical Therapeutic Chemical Classification (ATC) codes. Triptans (ATC code N02CC) were studied as one class. Other prescribed pain medications were non-steroidal anti-infammatory drugs (NSAIDs; M01AE and M01AB), paracetamol (NO2BE), coxibs $(\mathrm{M} 01 \mathrm{AH})$ and opioids in combination with analgesics (N02AJ). Antiemetics (A03FA) included metoclopramide, and prophylactic medications were defined to include non-selective monoamine reuptake inhibitors (N06AA), angiotensin receptor two blockers (C09CA), selective beta blockers (C07AB), other antiepileptics (including topiramate [NO3AX]), botulinum toxin (M03AX) and other antidepressants (including venlafaxine and mirtazapine [N06AX]).

\section{Statistical methods}

Patient characteristics, including age at erenumab initiation, follow-up length and medications, were assessed. Mean and standard deviation (SD) of age were reported as well as number and proportion of patients in specific age groups. Medications were assessed from the prescriptions recorded in the 12-month time period pre- and post-index. Patient numbers and proportions of patients receiving specific types of prescription are reported. Changes in medications, on a group level, were assessed pre- and post-index using McNemar's test and the $p$ values reported. Per patient year estimates of sick leave days and health care visits were calculated by dividing the total number of sick leave days and visits by length of the follow-up (either 1 year or half a year) pre- and post-index. The differences pre-index versus post-index were tested using the Wilcoxon signed rank test. The chi-squared test was used to test for changes in the proportion of patients in groups divided 
by the number of sick leaves and healthcare visits pre- and post-index. $P$ values were reported. A $p$ value $<0.05$ was considered to be statistically significant. No multiple testing correction was applied due to the small number of tests and likely correlated outcomes.

\section{RESULTS}

We identified 47,174 patients with a diagnosis of migraine in the database who had provided consent. Of these, 599 patients had been prescribed erenumab during the observation period, of whom $27 \%$ were entitled to employersponsored occupational health care $(n=162$; Fig. 1). One half of these 162 patients $(50.1 \%$, $n=82$ ) met the responder definition of $\geq 2$ erenumab prescriptions with no evidence of switch to other CGRP inhibitors (CGRPi) and were thus included in the main analyses (Fig. 1). Of the 82 patients included in the analysis, the majority of erenumab users were women (85\%), and the mean $( \pm S D)$ age of the cohort at initiation of erenumab treatment was $45 \pm$ 10 years (Table 1 ). In the previous 12 months, $68 \%$ of the patients had a prescription for a triptan, $68 \%$ for other pain medications and $66 \%$ for another prophylactic medication. The most common specified comorbid conditions treated in the 12 months pre index in patients receiving erenumab were acute respiratory tract infections (35\%), dorsalgia (15\%), other headache syndromes (13\%), malaise and fatigue $(11 \%)$, depressive episodes (11\%) and sleep disorders $(10 \%)$.

Patients receiving erenumab had a statistically significant reduction in the number of headache-related sick leave days, showing a $73.9 \%$ decrease in the 12 months post-index (pre-index vs. 12 months post-index: 4.9 vs. 1.3 sick leave days per patient-year; $p=0.035$; Fig. 2a). In the year preceding erenumab treatment, $31.5 \%$ of patients had at least 1 sick leave day due to headache; this proportion decreased to $17.1 \%$ in the year following the initiation of erenumab treatment $(p=0.04$; Electronic Supplementary Material [ESM] Fig. S1).

We observed that the number of headacherelated health care visits decreased by $44.6 \%$ in

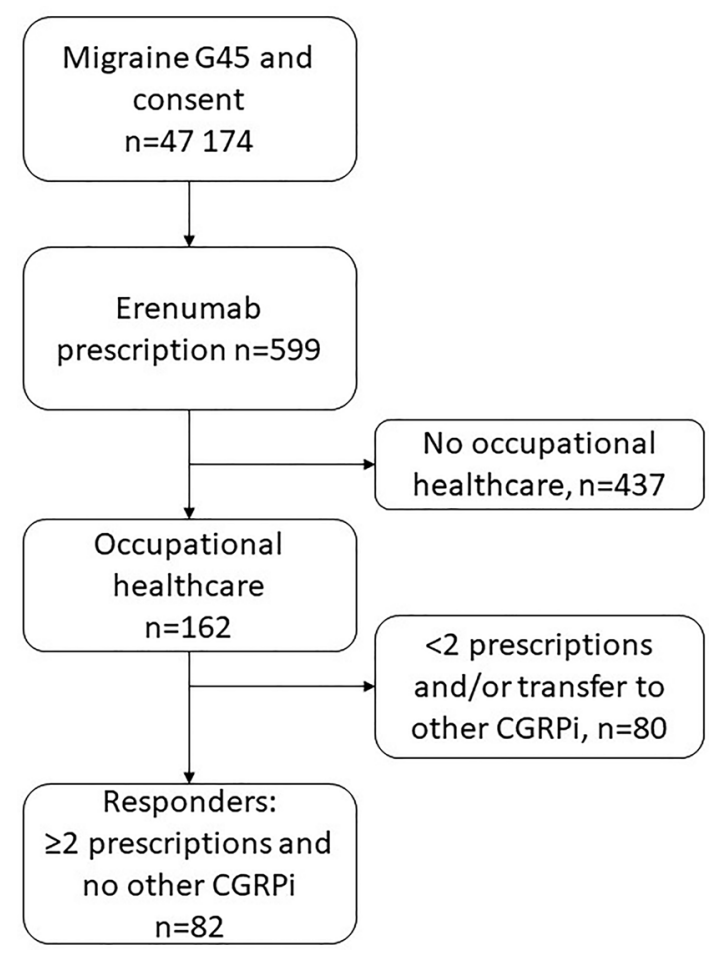

Fig. 1 Erenumab responders and flow chart of cohort generation. CGRPi Calcitonin gene-related peptide inhibitor, G45 ICD-10-CM code for migraine

the 12 months following initiation of erenumab treatment (pre-index vs. 12 months post-index: 4.9 vs. 2.7 visits per patient-year; $p<0.001$; Fig. 2b). The proportion of patients with $\geq 5$ visits related to headache decreased from $40.2 \%$ to $15.9 \%$ after initiation of erenumab treatment $(p=0.001$; ESM Fig. S1).

In the sensitivity analyses, the reduction in the number of headache-related sick leave days and health care visits at 6-12 months post-index was similar to the reduction at 0-12 months post-index (Fig. 2a, b). In contrast, the number of all-cause sick leave days and health care visits were unchanged in the 12 months post index versus pre index (Fig. 2c, d), although we did observe a reduction in the number of all-cause health care visits at 6-12 months post-index (Fig. 2d). There were no changes in headacherelated or all-cause health care visits or sick leave days in the control group (Fig. $2 a-d$ ).

The proportion of patients with a triptan prescription was reduced significantly from $68 \%$ pre-index to $48 \%$ post index $(-30 \% ; p=0.012)$ 
Table 1 Characteristics of erenumab responder patients and control group at the time of erenumab treatment initiation

\begin{tabular}{|c|c|c|}
\hline Variable & $\begin{array}{l}\text { Erenumab } \\
\text { responder } \\
\text { patients } \\
(N=82)\end{array}$ & $\begin{array}{l}\text { Migraine } \\
\text { controls } \\
(N=82)\end{array}$ \\
\hline Female $(n, \%)$ & $70(85 \%)$ & $70(85 \%)$ \\
\hline $\begin{array}{l}\text { Follow-up time, months } \\
\text { (mean) }\end{array}$ & 12 & 12 \\
\hline Age, years (mean, SD) & $45(10)$ & $45(10)$ \\
\hline \multicolumn{3}{|l|}{$\begin{array}{l}\text { Age distribution, years, } \\
\%\end{array}$} \\
\hline$<30$ & $6 \%$ & $6 \%$ \\
\hline $30-40$ & $23 \%$ & $23 \%$ \\
\hline $40-50$ & $40 \%$ & $40 \%$ \\
\hline $50-60$ & $22 \%$ & $22 \%$ \\
\hline $60-70$ & $9 \%$ & $9 \%$ \\
\hline \multicolumn{3}{|l|}{$\begin{array}{l}\text { Medications } \\
\text { (prescriptions in } 12 \\
\text { months pre-index) }\end{array}$} \\
\hline \multicolumn{3}{|l|}{ Triptans, \% } \\
\hline $\begin{array}{l}\text { Selective serotonin } \\
5 \mathrm{HT}_{1} \text { agonists } \\
\text { (triptans), N02CC }\end{array}$ & $68 \%$ & $39 \%$ \\
\hline \multicolumn{3}{|l|}{$\begin{array}{l}\text { Other pain medication, } \\
\%\end{array}$} \\
\hline $\begin{array}{l}\text { Propionic acid } \\
\text { derivatives, M01AE }\end{array}$ & $43 \%$ & $35 \%$ \\
\hline Paracetamol, N02BE & $21 \%$ & $12 \%$ \\
\hline $\begin{array}{l}\text { Opioids in } \\
\text { combination with } \\
\text { non-opioid analgesics, } \\
\text { N02AJ }\end{array}$ & $18 \%$ & $5 \%$ \\
\hline Coxibs, M01AH & $16 \%$ & $10 \%$ \\
\hline $\begin{array}{l}\text { Acetic acid derivatives, } \\
\mathrm{M} 01 \mathrm{AB}\end{array}$ & $15 \%$ & $9 \%$ \\
\hline $\begin{array}{l}\text { Combined, other pain } \\
\text { medication }\end{array}$ & $68 \%$ & $33 \%$ \\
\hline
\end{tabular}

Table 1 continued

\begin{tabular}{lll}
\hline Variable & $\begin{array}{l}\text { Erenumab } \\
\text { responder } \\
\text { patients } \\
(N=82)\end{array}$ & $\begin{array}{l}\text { Migraine } \\
\text { controls } \\
(N=82)\end{array}$ \\
\hline
\end{tabular}

Antiemetics, \%

Propulsives

$13 \%$

$1 \%$

(metoclopramide),

A03FA

Prophylactic

medication, \%

Non-selective

$31 \%$

$9 \%$

monoamine reuptake

inhibitors, N06AA

Angiotensin II

$31 \%$

$10 \%$

receptor blockers,

C09CA

Other antidepressants

$21 \%$

$5 \%$

(incl. venlafaxine, mirtazapine), N06AX

Other antiepileptics $\quad 20 \%$

(including

topiramate), N03AX

Selective beta blockers, $15 \%$

$11 \%$

$\mathrm{C} 07 \mathrm{AB}$

Muscle relaxants

$11 \%$

$0 \%$

(botulinum toxin),

M03AX

Combined,

$66 \%$

$23 \%$

prophylactic

medication

Other medication, \%

Proton pump

$28 \%$

$21 \%$

inhibitors, A02BC

Corticosteroids,

$17 \%$

$11 \%$

R01AD

Sympathomimetics, $\quad 16 \%$

$13 \%$ 
Table 1 continued

\begin{tabular}{|c|c|c|}
\hline Variable & $\begin{array}{l}\text { Erenumab } \\
\text { responder } \\
\text { patients } \\
(N=82)\end{array}$ & $\begin{array}{l}\text { Migraine } \\
\text { controls } \\
(N=82)\end{array}$ \\
\hline $\begin{array}{l}\text { Other centrally acting } \\
\text { agents (incl. } \\
\text { tizanidine), M03BX }\end{array}$ & $16 \%$ & $11 \%$ \\
\hline $\begin{array}{l}\text { Selective serotonin } \\
\text { reuptake inhibitors, } \\
\text { N06AB }\end{array}$ & $13 \%$ & $6 \%$ \\
\hline $\begin{array}{l}\text { Natural and } \\
\text { semisynthetic } \\
\text { estrogens, G03CA }\end{array}$ & $12 \%$ & $0 \%$ \\
\hline $\begin{array}{l}\text { Benzodiazepine } \\
\text { derivates, N05BA }\end{array}$ & $11 \%$ & $7 \%$ \\
\hline $\begin{array}{l}\text { Comorbid conditions } \\
\text { (visits with specific } \\
\text { ICD code in } \\
12 \text { months pre- } \\
\text { index), \% }\end{array}$ & & \\
\hline $\begin{array}{l}\text { Acute upper } \\
\text { respiratory infections } \\
\text { of multiple and } \\
\text { unspecified sites, J06 }\end{array}$ & $35 \%$ & $43 \%$ \\
\hline Dorsalgia, M54 & $15 \%$ & $11 \%$ \\
\hline $\begin{array}{l}\text { Other headache } \\
\text { syndromes, G44 }\end{array}$ & $13 \%$ & $7 \%$ \\
\hline $\begin{array}{l}\text { Malaise and fatigue, } \\
\text { R53 }\end{array}$ & $11 \%$ & $4 \%$ \\
\hline $\begin{array}{l}\text { Depressive episode, } \\
\text { F32 }\end{array}$ & $11 \%$ & $4 \%$ \\
\hline $\begin{array}{l}\text { Sleep disorders not } \\
\text { due to a substance or } \\
\text { known physiological } \\
\text { condition, F51 }\end{array}$ & $10 \%$ & $1 \%$ \\
\hline $\begin{array}{l}\text { Other and unspecified } \\
\text { dorsopathies, not } \\
\text { elsewhere classified, } \\
\text { M53 }\end{array}$ & $9 \%$ & $10 \%$ \\
\hline
\end{tabular}

Table 1 continued

\begin{tabular}{lll}
\hline Variable & $\begin{array}{l}\text { Erenumab } \\
\text { responder } \\
\text { patients } \\
(\boldsymbol{N}=\mathbf{8 2})\end{array}$ & $\begin{array}{l}\text { Migraine } \\
\text { controls } \\
(\boldsymbol{N}=\mathbf{8 2})\end{array}$ \\
\hline $\begin{array}{l}\text { Acute bronchitis, J20 } \\
\text { Infectious }\end{array}$ & $7 \%$ & $2 \%$ \\
gastroenteritis and \\
colitis, unspecified, \\
A09
\end{tabular}

ICD International Classification of Diseases, Tenth Revision, Clinical Modification, SD Standard deviation Codes following name of medication are the Anatomical Therapeutic Chemical Classification (ATC) codes

among patients receiving erenumab. In the same group, the proportion of patients receiving a prescription for prophylactic medication other than erenumab was reduced significantly from $66 \%$ pre-index to $45 \%$ post-index (-32\%; $p=0.004$ ) (Fig. 3a). No significant changes were observed in prescriptions for other pain medications in erenumab users or in any of the included prescriptions in the control group (Fig. 3b).

\section{DISCUSSION}

In this study we investigated the impact of erenumab on the number of sick leave days and health care visits, as well as on medication prescriptions in employed patients with migraine using data retrieved from electronic health records. This study brings new insight into the effect of erenumab on sick leave days as well as health care visits among erenumab 

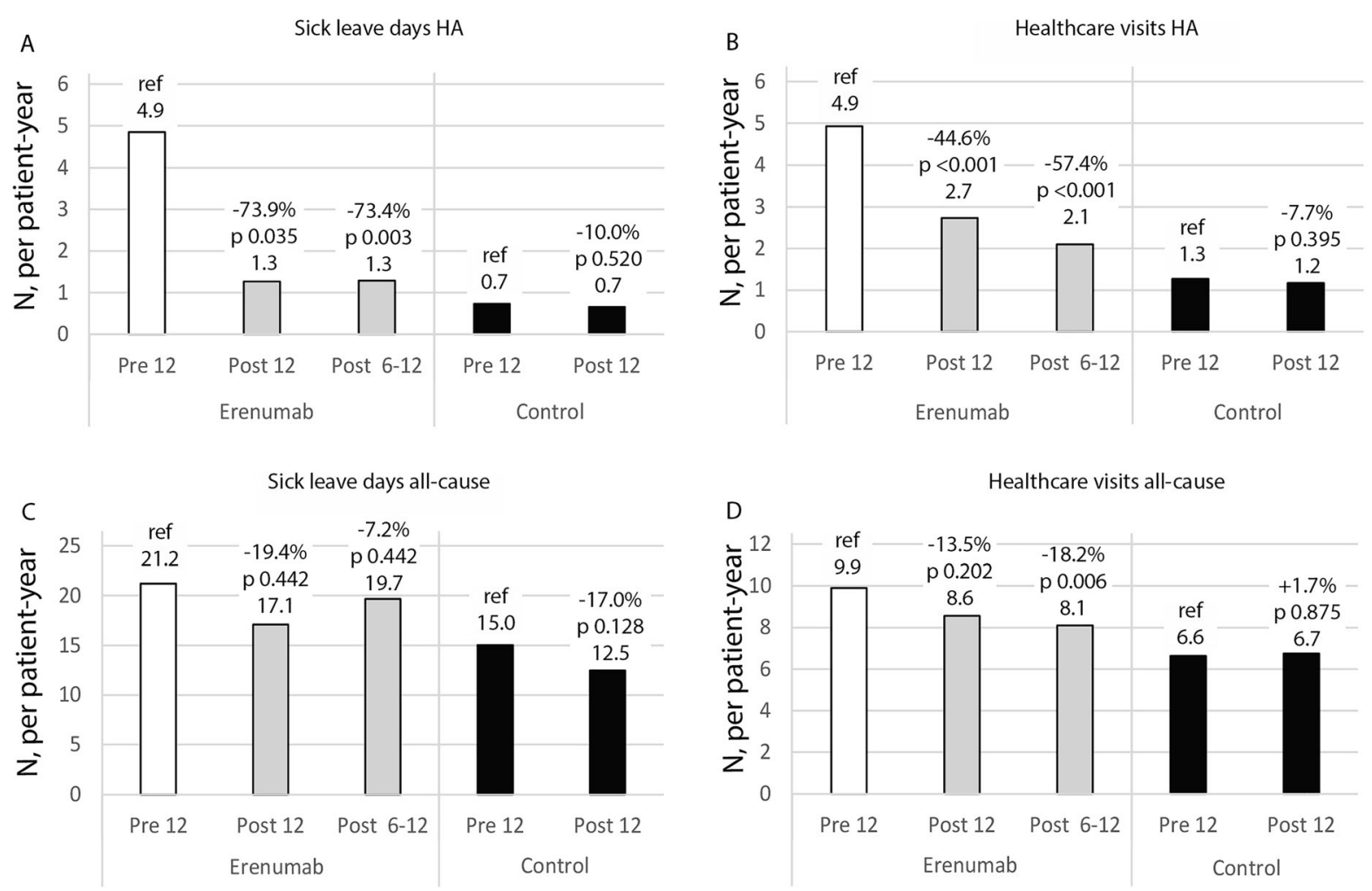

Fig. 2 Change in headache-related $(H A)$ and all-cause sick leave days and health care visits in patients on erenumab treatment and in age- and gender-matched controls. $P$ value compared to reference (12 months pre-index)

responders, where headache-related sick leave days were reduced by $73.9 \%$ and health care visits by $44.6 \%$. Despite the significant number of clinical studies demonstrating the benefit of erenumab on migraine days $[14,16-18]$, there is limited information available on the impact of erenumab on occupationally active patients with regards to the effect on sick leave days and health care visits in the real-world setting.

The observed reduction in number of sick leave days in this study is supported by the post hoc analysis of a phase 2 clinical trial, in which patients with chronic migraine reported that erenumab decreased both absenteeism and presenteeism as well as combined all-cause work impairment compared to placebo, with fewer patients experiencing severe or very severe disability [23]. In addition, a recent survey study suggests that erenumab reduces working impairment also in patients with chronic migraine and medication overuse [25]. Our study corroborates these findings with realworld data from electronic health records.
While the observed reduction in number of sick leave days in our study is undoubtedly important, it should be noted that absenteeism represents only part of the overall working impairment related to migraine $[2,5,9]$. Our study focused on sick leave days and health care visits, and we do not have information about the potential effect of erenumab on presenteeism in the form of improved working productivity, an area which warrants future research.

We also observed that a minority of patients receiving erenumab accounted for the majority of headache-related sick leave days. In fact, the data showed that almost two out of three patients did not have headache-related sick leave days in their records in the year preceding erenumab treatment. While many patients report working impairment due to migraine, our study suggests that actual headache-related absenteeism may be concentrated in a relatively small number of patients with a very significant burden of disease. We cannot, however, exclude 


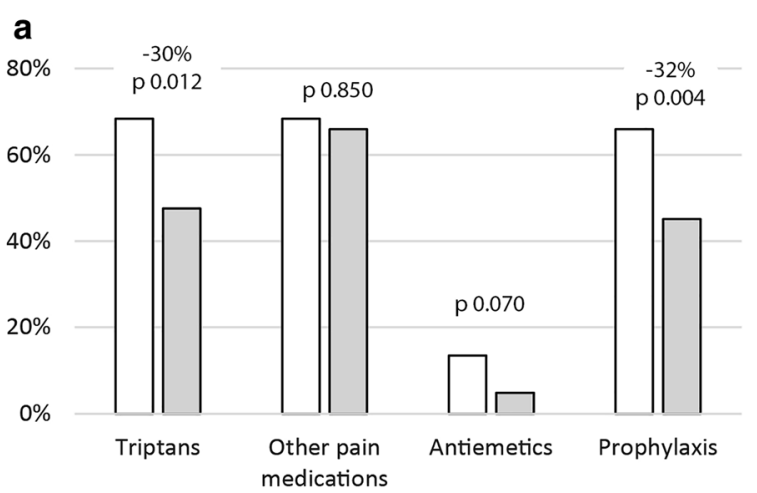

Fig. 3 Prescription changes in patients treated with erenumab (a) and in controls (b) in 12 months pre-index (white) and in 12 months post-index (gray shading)

the possibility that some of the short-term sick leaves allowed on employees own notice would not be captured in the electronic health records.

Previous studies suggest that both absenteeism and productivity loss increase steeply in patients with chronic migraine versus episodic migraine $[8,9]$. Unfortunately, without information about MMDs in the registry data we were unable to stratify the patients based on disease severity. During the study erenumab was available in Finland for patients with episodic or chronic migraine with $\geq 8$ MMDs and $\geq 2$ failed prophylactic treatments; these criteria define the minimum severity of the migraine in patients included in our study. Future studies should address the real-life effect of erenumab on sick leave days in patients with migraine of clearly defined severity in more detail.

The reduction in the number of headacherelated sick leave days and health care visits was similar when assessing the full 12-month postindex period and the 6 - to 12 -month post-index period, indicating that the full treatment effect on these parameters was achieved as early as within the first 6 months after treatment initiation. Changes in the number of all-cause sick leave days and health care visits were smaller and not statistically significant, possibly explained by the limited number of patient and short follow-up time.

The effect of erenumab on absenteeism and health care use are likely to be additive to and dependent on the clinical effect of erenumab on

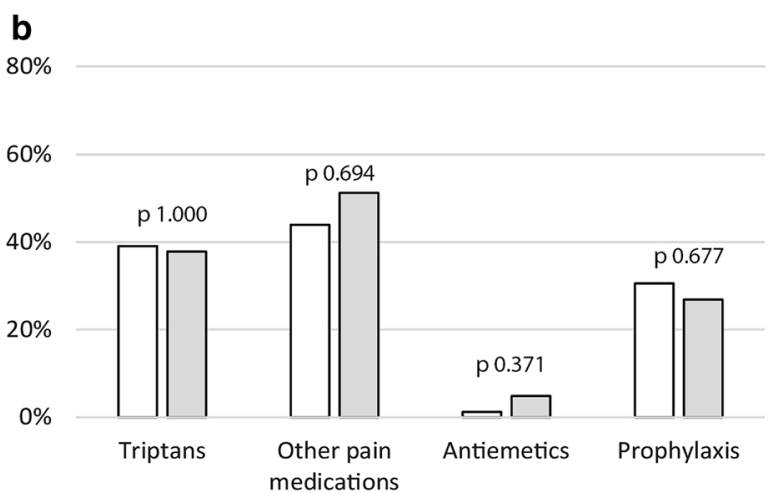

$P$ values (12 months pre-index vs. post-index) for medication groups based on prescriptions

the severity of migraine. We therefore studied the impact of erenumab on sick leave days and visits in patients with a treatment response to erenumab indicated by continuous use of the drug. This responder criterion was based on the national reimbursement criterion for erenumab requiring a 50\% reduction in MMDs at 12 weeks from treatment initiation for continued reimbursement and, therefore, for a second erenumab prescription. Consequently, the $50 \%$ of patients receiving the second erenumab prescription have likely experienced a reduction of at least $50 \%$ in their MMDs. While this is an indirect assessment, this proportion of responders as defined in our study is in line with responder rates reported in other real-world studies, ranging from $35 \%$ to $58 \%$ of patients reporting $>50 \%$ reduction in MMDs $[19,21,22]$.

In addition to the reduction in headacherelated sick leave days and health care visits, we also observed changes in medication prescription patterns after erenumab treatment initiation. The proportion of patients prescribed triptans was reduced by $30 \%$, indicating that there is a reduced need for acute migraine medication after erenumab treatment, as would be expected from the reduced number of MMDs with erenumab documented previously [14, 16-18]. Our finding is consistent with the results from a recent large retrospective cohort study in the USA in which $36.5 \%$ of the patients on erenumab discontinued triptan use within 
300 days of erenumab initiation [26]. Furthermore, a recent registry study highlighted that more than $50 \%$ of patients receiving erenumab experienced improvement in triptan effectiveness, which could at least partially explain the reduced prescriptions observed in our study [27]. Interestingly, the proportion of patients with prescriptions for other pain medications than triptans remained unchanged in our study, suggesting that erenumab may specifically reduce the use of triptans.

We also observed a $32 \%$ reduction in the number of prescriptions for drugs commonly used for migraine prophylaxis. Regrettably, we do not know if these drugs were in fact prescribed for migraine prevention or for some other indication. However, as no significant changes in this category of prescribed medications were evident in the control group, the observed changes are likely related to erenumab treatment. Again, this reduction is of similar magnitude to that reported in recent study by Hines et al. [26], who found a $36.1 \%$ reduction in prophylactic prescriptions after initiation of erenumab treatment.

The global COVID-19 pandemic coincided with the study period, which could have affected patient behavior and health care practices. However, no significant changes in either headache-related or all-cause-related sick leave days, health care visits or prescription patterns were observed in the control group, suggesting that the observed changes in these parameters were indeed related to erenumab treatment.

\section{Strengths and Limitations}

As this study is based on pre-collected registry data, it was subject to some limitations. Erenumab treatment initiation and response were based on prescriptions, and actual adherence to treatment could not be assessed. However, as the responders were defined as patients with two prescriptions, it is likely that patients who came back for a second prescription also adhered to the treatment. We also do not have information on the distribution of erenumab doses of $70 \mathrm{mg}$ and $140 \mathrm{mg}$ per month and therefore cannot conclude if the effect on sick leave days or health care visits was dependent on erenumab dose. We also cannot be sure that all sick leaves, especially those shorter than 3 days, were recorded and captured in the registry, because they may not always require an attestation from a physician. Furthermore, health care visits at other providers or public sector providers were not included in this study. Thus, the study results may be considered to be a conservative estimate of sick leave days and health care visits, marking the minimum of improvement in health. We also have limited information on the severity of migraine in our study participants as the number of headache days is not recorded in the registry. It is plausible that erenumab as a new treatment was first prescribed for patients with the highest burden on disease, and it is therefore impossible to estimate if the patient cohort represents average erenumab users in the long term.

Medication changes were assessed from prescriptions, and actual drug purchases or overthe-counter medications, as well as the indication for the prescription could not be assessed. The study included a relatively small number of migraine patients, and the length of follow-up was relatively short, reflecting the recent launch and reimbursement of erenumab at the time of the study analyses. In particular, our study may have been too short and the patient number too small to analyze the effect of erenumab on allcause sick leaves, all-cause health care visits and underlying comorbidities, which should be revisited in future studies.

Our findings can be best generalized to countries with similar health care systems and access to medicines as in Finland. Our responder criteria were based on the Finnish reimbursement system, and care must be taken when interpreting the results when looser or more stringent clinical criteria for patient selection and responder definition are applied. Furthermore, the economic impact of absenteeism on worker's personal income differs between countries and may therefore favor different kinds of behavior, such as presenteeism instead of absenteeism in countries where sick leaves have more direct impact on personal income. Furthermore, as this study is conducted in one country with a relatively unique genetic 
heritage, we cannot rule out the effect of genetic background on the results.

Even with these limitations, the study has significant strengths, such as reflection of the Finnish clinical practice for migraine patients, inclusion of a real-world patient population and outcomes that are measured in an unbiased way and are unaffected by plausible reporting or recollection biases often associated with surveys. Further strong points include the assessment of outcomes in a working age population from electronic health records with longitudinal follow-up.

\section{CONCLUSION}

This registry study on data retrieved from electronic health records suggests that the effect of erenumab on monthly number of migraine days documented in both clinical trials and realworld studies translates into a reduced number of headache-related sick leave days and health care visits in employed patients with migraine managed in routine clinical practice.

\section{ACKNOWLEDGEMENTS}

We would like to thank Mrs. Christel Haar Rendsvig, Novartis Healthcare A/S, Copenhagen, Denmark for language revision.

Funding. The study and the journal's Rapid Service Fee was funded by Novartis Finland Oy, Espoo, Finland.

Authorship. All named authors meet the International Committee of Medical Journal Editors (ICMJE) criteria for authorship for this article, take responsibility for the integrity of the work as a whole, and have given their approval for this version to be published.

Authors' Contributions. Timo Purmonen, Mariann Lassenius, Emina Mocevic, Minna A Korolainen, Samuli Tuominen and Markku Nissilä contributed to study design. Henri Autio, Timo Purmonen, Emina Mocevic, Minna A Korolainen, Mariann I Lassenius, Samuli
Tuominen, Samu Kurki and Markku Nissilä contributed to interpretation of data and were involved in manuscript writing and revision. Samu Kurki, Samuli Tuominen and Markku Nissilä contributed to data acquisition and analyses. All authors gave final approval for manuscript publication and agreed to be accountable for all aspects of their work.

Prior Presentation. This manuscript is based on work previously shared at EAN virtual congress 2021 as an ePoster presentation by Nissilä et al. on June 21th 2021.

Disclosures. Henri Autio, Timo Purmonen and Minna A Korolainen were employed by Novartis Finland Oy and Emina Mocevic was employed by Novartis Healthcare A/S, Copenhagen, Denmark at the time of study. Samuli Tuominen and Mariann I Lassenius were employed by Medaffcon Oy, Espoo, Finland, and Samu Kurki and Markku Nissilä were employed by Terveystalo Biobank, Turku, Finland at the time of study. Minna A Korolainen is currently employed by Orion Oyj, Espoo, Finland and Samu Kurki is currently employed by ICON plc, Dublin, Ireland. Erenumab is co-developed by Amgen and Novartis.

Compliance with the Ethics Guidelines. As a non-interventional retrospective registry study this study was approved as a non-interventional retrospective registry study by the Terveystalo Institutional Review Board on 10 April 2019 (20190410-A) in accordance with the Data Protection Act (1050/2018), and access to the data was granted by Terveystalo. All patients had given their informed consent for secondary use of health data to Terveystalo in a format that has been approved by the National Institute of Health and Welfare, Finland. All data were analyzed in pseudonymized format and published in aggregate such that an individual subject cannot be identified. This study was performed in accordance with the Helsinki Declaration of 1964 and its later amendments.

Data Availability. The datasets generated during and/or analyzed during the current 
study are available from the corresponding author on reasonable request.

Open Access. This article is licensed under a Creative Commons Attribution-NonCommercial 4.0 International License, which permits any non-commercial use, sharing, adaptation, distribution and reproduction in any medium or format, as long as you give appropriate credit to the original author(s) and the source, provide a link to the Creative Commons licence, and indicate if changes were made. The images or other third party material in this article are included in the article's Creative Commons licence, unless indicated otherwise in a credit line to the material. If material is not included in the article's Creative Commons licence and your intended use is not permitted by statutory regulation or exceeds the permitted use, you will need to obtain permission directly from the copyright holder. To view a copy of this licence, visit http://creativecommons.org/licenses/by$\mathrm{nc} / 4.0 /$.

\section{REFERENCES}

1. Steiner TJ, Stovner LJ, Vos T, et al. Migraine is first cause of disability in under 50s: will health politicians now take notice? J Headache Pain 2018;19(1): 17 https://doi.org/10.1186/s10194-018-0846-2.

2. Hansson-Hedblom A, Axelsson I, Jacobson L, et al. Economic consequences of migraine in Sweden and implications for the cost-effectiveness of onabotulinumtoxinA (Botox) for chronic migraine in Sweden and Norway. J Headache Pain. 2020;21:99. https://doi.org/10.1186/s10194-020-01162-x.

3. Martelletti P, Schwedt TJ, Lanteri-Minet M, et al. My Migraine Voice survey: a global study of disease burden among individuals with migraine for whom preventive treatments have failed. J Headache Pain. 2018;19:115. https://doi.org/10.1186/s10194-0180946-z.

4. Stewart WF. Prevalence of migraine headache in the United States: relation to age, income, race, and other sociodemographic factors. JAMA. 1992;267: 64. https://doi.org/10.1001/jama.1992. 03480010072027.

5. Vestergaard SV, Rasmussen TB, Stallknecht S, et al. Occurrence, mortality and cost of brain disorders in
Denmark: a population-based cohort study. BMJ Open. 2020;10:e037564. https://doi.org/10.1136/ bmjopen-2020-037564.

6. Korolainen MA, Kurki S, Lassenius MI, et al. Burden of migraine in Finland: health care resource use, sick-leaves and comorbidities in occupational health care. J Headache Pain. 2019;20:13. https:// doi.org/10.1186/s10194-019-0964-5.

7. Linde M, Gustavsson A, Stovner LJ, et al. The cost of headache disorders in Europe: the Eurolight project. Eur J Neurol. 2012;19:703-11. https://doi.org/10. 1111/j.1468-1331.2011.03612.x.

8. Munakata J, Hazard E, Serrano D, et al. Economic burden of transformed migraine: results from the American Migraine Prevalence and Prevention (AMPP) study. Headache. 2009;49:498-508. https:// doi.org/10.1111/j.1526-4610.2009.01369.x.

9. Sumelahti M-L, Sumanen M, Sumanen MS, et al. My Migraine Voice survey: disease impact on healthcare resource utilization, personal and working life in Finland. J Headache Pain. 2020;21:118. https://doi.org/10.1186/s10194-020-01185-4.

10. Parikh SK, Young WB. Migraine: stigma in society. Curr Pain Headache Rep. 2019;23:8. https://doi. org/10.1007/s11916-019-0743-7.

11. Young WB, Park JE, Tian IX, Kempner J. The stigma of migraine. PLoS ONE. 2013;8:e54074. https://doi. org/10.1371/journal.pone.0054074.

12. Ament M, Day K, Stauffer VL, et al. Effect of galcanezumab on severity and symptoms of migraine in phase 3 trials in patients with episodic or chronic migraine. J Headache Pain. 2021;22:6. https://doi. org/10.1186/s10194-021-01215-9.

13. Ferrari $\mathrm{MD}$, Diener $\mathrm{HC}$, Ning $\mathrm{X}$, et al. Fremanezumab versus placebo for migraine prevention in patients with documented failure to up to four migraine preventive medication classes (FOCUS): a randomised, double-blind, placebo-controlled, phase 3b trial.Lancet. 2019;394:1030-40. https:// doi.org/10.1016/S0140-6736(19)31946-4.

14. Goadsby PJ, Reuter U, Hallström Y, et al. A controlled trial of erenumab for episodic migraine. N Engl J Med. 2017;377:2123-32. https://doi.org/ 10.1056/NEJMoa1705848.

15. Lipton RB, Goadsby PJ, Smith J, et al. Efficacy and safety of eptinezumab in patients with chronic migraine: PROMISE-2. Neurology. 2020;94: 1365-77. https://doi.org/10.1212/WNL. 0000000000009169. 
16. Dodick DW, Ashina M, Brandes JL, et al. ARISE: A Phase 3 randomized trial of erenumab for episodic migraine. Cephalalgia. 2018;2018:12.

17. Reuter U, Goadsby PJ, Lanteri-Minet M, et al. Efficacy and tolerability of erenumab in patients with episodic migraine in whom two-to-four previous preventive treatments were unsuccessful: a randomised, double-blind, placebo-controlled, phase 3b study. Lancet. 2018;392:2280-7. https://doi.org/ 10.1016/S0140-6736(18)32534-0.

18. Tepper S, Ashina M, Reuter U, et al. Safety and efficacy of erenumab for preventive treatment of chronic migraine: a randomised, double-blind, placebo-controlled phase 2 trial. Lancet Neurol. 2017;16:425-34. 4422(17)30083-2.

19. Lambru G, Hill B, Murphy M, et al. A prospective real-world analysis of erenumab in refractory chronic migraine. J Headache Pain. 2020;21:61. https://doi.org/10.1186/s10194-020-01127-0.

20. Ornello R, Casalena A, Frattale I, et al. Real-life data on the efficacy and safety of erenumab in the Abruzzo region, central Italy. J Headache Pain. 2020;21:32. https://doi.org/10.1186/s10194-02001102-9.

21. Robblee J, Devick KL, Mendez N, et al. Real-world patient experience with erenumab for the preventive treatment of migraine. Headache. 2020;60: 2014-25. https://doi.org/10.1111/head.13951.
22. Scheffler A, Messel O, Wurthmann S, et al. Erenumab in highly therapy-refractory migraine patients: first German real-world evidence. J Headache Pain. 2020;21:84. https://doi.org/10.1186/s10194-02001151-0.

23. Lipton RB, Tepper SJ, Reuter U, et al. Erenumab in chronic migraine: Patient-reported outcomes in a randomized double-blind study. Neurology. 2019;92:e2250-60. https://doi.org/10.1212/WNL. 0000000000007452 .

24. Korolainen MA, Tuominen S, Kurki S, et al. Burden of migraine in Finland: multimorbidity and phenotypic disease networks in occupational healthcare. J Headache Pain. 2020;21:8. https://doi.org/ 10.1186/s10194-020-1077-x.

25. Cainazzo MM, Baraldi C, Ferrari A, et al. Erenumab for the preventive treatment of chronic migraine complicated with medication overuse headache: an observational, retrospective, 12-month real-life study. Neurol Sci. 2021. https://doi.org/10.1007/ s10072-021-05105-5.

26. Hines DM, Shah S, Multani JK, et al. Erenumab patient characteristics, medication adherence, and treatment patterns in the United States. Headache. 2021;61: 590-602. https://doi.org/10.1111/head.14068.

27. Frattale I, Caponnetto V, Casalena A, et al. Association between response to triptans and response to erenumab: real-life data. J Headache Pain. 2021;22: 1. https://doi.org/10.1186/s10194-020-01213-3. 